\title{
Interactive physiological potential of Peyronellaea curtisii (=Phoma narcissi) strains for enzymatic attack and defence capabilities against phytoalexins
}

\author{
Katarzyna Hrynkiewicz • Pawel Deka • Malgorzata Ruszkiewicz-Michalska • \\ Dominika Thiem • Adriana Szmidt-Jaworska
}

Accepted: 9 November 2015 / Published online: 18 November 2015

(C) The Author(s) 2015. This article is published with open access at Springerlink.com

\begin{abstract}
Phytopathogenic fungi use a variety of strategies to infect hosts and have a diverse sensitivity to the natural defence mechanisms of the host plant, e.g. synthesis of phytoalexins. Many important pathogens of crops belong to the problematic genus Phoma, including species recently reallocated to Peyronellaea. The work presents: (1) molecular identification of five pathogenic strains of Peyronellaea (syn. Phoma) based on two loci, actin (ACT) and $\beta$-tubulin (TUB), and morphological observations; (2) differentiation of these strains based on their enzymatic activity; and (3) their effect on biosynthesis of phytoalexin in Hippeastrum scales. Phylogenetic analysis showed a close relationship between our strains and Peyronellaea curtisii (syn. Phoma narcissi) species. This was also supported by morphoanatomical analysis although its results were less conclusive. Some phenotypic traits of the strains overlapped with characteristics of other Phoma s.l. species, allowing for misidentification based on morphology
\end{abstract}

K. Hrynkiewicz $(\bowtie) \cdot$ P. Deka $\cdot$ D. Thiem

Department of Microbiology, Faculty of Biology and

Environment Protection, Nicolaus Copernicus University,

Lwowska 1, PL-87-100 Torun, Poland

e-mail: hrynk@umk.pl

A. Szmidt-Jaworska

Chair of Plant Physiology and Biotechnology, Faculty of Biology and Environment Protection, Nicolaus Copernicus University,

Lwowska 1, PL-87-100 Torun, Poland

M. Ruszkiewicz-Michalska

Department of Algology and Mycology, Faculty of Biology and Environmental Protection, University of Lodz, Banacha 12/16, PL90-237 Lodz, Poland alone. Tested cellulolytic, pectolytic and amylolytic activities were strain specific. A high level of amylase activity was positively correlated with cellulase activity but negatively correlated with pectolytic activity. Moreover, some strains suppressed phytoalexin production in Hippeastrum scales and were resistant to various concentrations of phytoalexin added to the culture medium. Based on these results, we suggest that pathogenicity in $P$. curtisii strains is complex and that it may be associated with their interactive physiological potential for enzymatic attack and defence capabilities against phytoalexin.

Keywords Phytopathogenic fungi • Enzymatic activity · Phytoalexins · $\beta$-tubulin (TUB) · Actin (ACT) ·

Dothideomycetes $\cdot$ Hippeastrum disease

\section{Introduction}

Genus Peyronellaea (Dothideomycetes), valildy introduced in 1952 by Goidànich, was synonymized with Phoma and included in section Peyronellaea by Boerema and co-workers in 1960s (Boerema et al. 2004). Recently Peyronellaea genus has been reestablished as an effect of molecular studies of Phoma s.l. phylogeny (Aveskamp et al. 2010). The half of the species previously accommodated in Peyronellaea section as well as a dozen of taxa from other Phoma sections (including Ph. narcissi $=$ Peyronellaea curtisii) have been recombined into the newly re-instated genus. Currently, Peyronellaea genus comprises of 66 taxa, 
including 24 taxa accepted in the genus by Aveskamp et al. (2010) and two plant-associated species newly described by Crous et al. (2013) as well as 40 unverified species (Index Fungorum 2015). Peyronellaea groups a small part of members of the coelomycetous genus Phoma s.l. that is one of the largest fungal genera, with more than 3000 infrageneric taxa described (Monte et al. 1991). In course of future studies the number of Peyronellaea species is likely to increase enlarged by other Phoma s.l. species. Majority of Peyronellaea members were isolated from plants (including pathogens) but some species were also reported from plant products, soil and animal or inorganic substrata (Boerema et al. 2004; Aveskamp et al. 2010).

Approximately $50 \%$ of Phoma s.l. species are phytopathogens (Boerema et al. 2004; Aveskamp et al. 2008). However, Phoma s.l. strains have also been isolated from soil, aerial and aquatic environments, and even from humans and animals, where they cause opportunistic infections (Irinyi et al. 2009). Plant diseases caused by Phoma spp. can occur under favourable environmental conditions and result in leaf and stem spots and significant yield losses (Aveskamp et al. 2008). Phoma s.l. is one of the most ubiquitous fungal genera, characterised by its great ecological diversity and difficult identification (Aveskamp et al. 2010). The large number of described species is due to the common practice of host associated nomenclature, paucity in the micro-morphological features, and a high variability in culture characteristics. Because of these problems, the systematics of the Phoma s.l. genus has never been fully understood (Aveskamp et al. 2008). To solve this problem, a comprehensive taxonomic system is required based on DNA techniques (Aveskamp et al. 2010) or DNA barcodes that are used in the rapid detection of potentially serious plant pathogens (Armstrong and Ball 2005). In recent years actin (ACT) and $\beta$-tubulin (TUB) genes have been proposed as standard loci for use in DNA barcoding in selected genera of fungi (Aveskamp et al. 2009a, 2009b). These genes are so-called housekeeping genes that encode for proteins required for the basic functioning of every cell. Moreover, the integration of morphological and culture features with DNA sequence data can resolve the genetic limits of the taxa that have been placed in Didymellaceae. De Gruyter et al. (2009) found a series of genera clustering in the Didymellaceae that were not clearly defined or were morphologically distant from each other. Therefore, the further development of Phoma s.l. (including
Peyronellaea) taxonomy should be based on a combination of data from phylogenetic and morphological studies.

In the present paper, the authors present physiological properties of Peyronellaea strains that are associated with phytopathogenicity. Fungal pathogens synthesise large amounts of cell wall degrading enzymes (CWDE), including pectinases, xylanases, cellulases, and proteases, which are capable of depolymerising various components of the host cell wall (Tonukari 2003). Pathogens differ in terms of quantity and diversity of enzyme secretion. Fungi causing plant cell death release a large quantity of cell wall degrading enzymes, whereas pathogens that require a living host to provide nutrients minimise the production of such enzymes (Horbach et al. 2011). Therefore, differences in physiological activity can be a key factor in differentiating Peyronellaea strains according to their pathogenicity.

The interaction between plants and their pathogens is complex and vary depending on the plant and the fungus. The defence strategies of plants against their pathogens are many fold and include the synthesis of phytoalexins. Phytoalexins are a group of chemically diverse broad-spectrum antimicrobial compounds that plants synthesise in response to wounding and pathogen attack. Many studies have shown that phytoalexins play a role in plant disease resistance (Dixon 2001). Most phytoalexins, which are an important element of plants' active defence mechanisms, have been reported to be highly fungitoxic. For example, potato (Solanum tuberosum) tubers produce lubimin (a sesquiterpene phytoalexin) upon infection, which inhibits the growth of a variety of microorganisms (Kuć 1982). Malusfuran, the phytoalexin that is produced in apple (Malus domestica), can inhibit spore germination and the growth of Venturia inaequalis at millimolar concentrations (Hrazdina et al. 1997). The phytoalexin resveratrol, such as medicarpin, can inhibit the hyphal growth of the alfalfa fungal pathogen Phoma medicaginis (Dixon 2001). Pisatin from pea inhibits mycelial growth of several fungi, including both pathogens and nonpathogens of pea (Delserone et al. 1999). The same is true for momilactones A and B and phytocassanes A from rice (Hasegawa et al. 2010). The ethanol extract of wyerone acid could significantly reduce Botrytis fabae spore germination with increased concentration, although phytoalexin had no effect on in vitro germ tube growth of the fungus (Nawar and Kuti 2003). In this work, the ornamental bulbous plant of the genus 
Hippeastrum and its Peyronellaea pathogens were used as a model for phytoalexin - fungal interaction. Various organs of Hippeastrum that are Peyronellaea-infected or mechanically wounded produce red pigment on the surface of injured tissues. Chemical analysis revealed that red pigment produced upon wounding of Hippeastrum $\mathrm{x}$ hortorum bulbs is a mixture composed of an orange-coloured chalcone and 3 flavans (Wink and Lehmann 1996). After mechanical injuries, when intensive reddish colouration is developed on the scales and basal plate of Hippeastrum plants, the subsequent fungal disease symptoms are much weaker (Saniewska and Budzianowski 1997). One approach to improve Hippeastrum spp. resistance to fungi could therefore be to culture plant genotypes producing anti-fungal phytoalexins. Therefore, analysing the correlation between Peyronellaea infection and host production of phytoalexin is an important area of research.

The aim of this study was to identify five Peyronellaea strains based on an analysis of TUB and ACT loci compared with morphological data, and to evaluate the diversity of their metabolic activity. Moreover, the ability of the tested strains to inhibit phytoalexin biosynthesis was determined. Finally, the impact of phytoalexins on mycelium growth was analysed. We hypothesised that Peyronellaea strains with a higher potential for hydrolytic enzymes production and hence higher pathogenicity would correlate with the sensitivity of fungal strains to phytoalexins.

\section{Materials and methods}

Morphological characterisation of fungal strains

In this study, we used five Peyronellaea strains marked as P2, P4, P6, P10 and P80; these strains were isolated from the infected bulbs of Knight's star lilly (Hippeastrum $\times$ hybridum hort.) variety Jan. (obtained courtesy of the Research Institute of Pomology and Floriculture in Skierniewice, Poland). Fungal strains were selected for our experiment based on morphological differences in their colony growth on potato dextrose agar (PDA) (Difco). Strains were first cultivated on PDA in Petri dishes and tubes at $26{ }^{\circ} \mathrm{C}$ and stored at $4{ }^{\circ} \mathrm{C}$. Thereafter strain diversification was performed on media standard for Phoma-like fungi (Boerema et al. 2004): oatmeal agar (OA) and malt-extract agar (MEA)
(Difco) in $9 \mathrm{~cm}$ Petri dishes at $24-26{ }^{\circ} \mathrm{C}$ in complete darkness for 8 days. Next, the cultures were exposed to UV light (dark interval of 11:13, 12 days) to induce sporulation. The colonies were characterized based on growth rate, pigment formation, colony pattern and outline, $\mathrm{NaOH}$ test on OA and MEA. The micromorphological studies included the light microscope determination of features of hyphae, pycnidia, conidia and chlamydospores produced on OA. The structures were measured ( $8-10$ conidiogenous cells and pycnidial wall cells, and 30 conidia) to present the range of size variation.

Molecular identification of fungal strains by PCR and sequencing

The DNA sequences of the ACT and TUB regions were initially used to identify the fungal strains used in the experiment. DNA was isolated from mycelium of the fungal strains growing on PDA using the DNAeasy Plant Mini Kit (Qiagen, Hilden, Germany) according to the manufacturer's instructions. The actin gene (ACT) was amplified with primer pair ACT-512F and ACT-783R (Carbone and Kohn 1999) and the $\beta$-tubulin gene (TUB) with primer pair TUB2Fd and TUB4Rd (Aveskamp et al. 2009a). For the two housekeeping genes ACT and TUB, each PCR reaction was done according to Aveskamp et al. (2009a) with the use of Master Mix Taq (Qiagen). The PCR products obtained were purified using the QIAquick protocol (Qiagen). Direct sequencing of PCR products was performed using the PCR primers as sequencing primers. Sequences were aligned manually by the Sequencher system (TW Version 5.1, Gene Codes, Ann Arbor, MI, USA). BLAST searching with ACT/TUB-sequences was performed on the GenBank (Altschul et al. 1990) and Q-bank (http://www.q-bank.eu/fungi) servers. The DNA sequences determined for this study were submitted to GenBank, and the accession numbers are: KT986199, KT986200, KT986201, KT986202, KT986203 (Fig. 3) and KT986194, KT986195, KT986196, KT986197, KT986198 (Fig. 4).

Phylogenetic analysis

TUB and ACT sequences with closest BLAST matches were aligned with other published sequences (NCBI and Q-bank) using Clustal W (Thompson et al. 1997). Phylogenetic relationships were investigated using 
PAUP, version 4.0b10 (Swofford 2003): Neighbourjoining analyses (NJ; Saitou and Nei 1987) were done with Kimura 2-parameter genetic distances (Kimura 1980), combined with bootstrap analyses (Felsenstein 1985) from 1000 replicates. If several sequences of the same species were presented in the GenBank and if they clustered together, only one sequence was included in the final tree.

Fungal enzyme activities

All five strains of Peyronellaea strains (P2, P4, P6, P10 and $\mathrm{P} 80$ ) were examined for their potential metabolic activity. The following methods were used in the determination of enzymatic activities: amylolytic activity (Gibson and Gordon 1974), cellulolytic activity and pectolytic activity (Strzelczyk and Szpotański 1989). These methods are based on the hydrolysis of the following substances: starch (amylolytic activity), pectin (pectolytic activity) and carboxymethylcellulose (CMC) (cellulolytic activity). All five strains were used for each assay, with three replicates per strain and three measurements for each replicate $(n=9)$. Coefficients of activity $\left(\mathrm{W}_{\text {act }}\right)$ were calculated as follows:

$\mathrm{W}_{\mathrm{act}}=\mathrm{S}_{\mathrm{h}}{ }^{2} /\left(\mathrm{S}_{\mathrm{c}} \times \mathrm{t}\right)$,

where $S_{h}$ is the diameter of the hydrolysis zone, $S_{c}$ is the diameter of the colony, and $t$ is the incubation time (Hrynkiewicz et al. 2010).

Elicitation of phytoalexin (PA) production

in Hippeastrum scales and its isolation

PA was extracted from Hippeastrum scales, which were wounded to elicit its production. Scales were cut into small pieces $(5 \times 5 \mathrm{~mm})$ and incubated for $72 \mathrm{~h}$ in a closed chamber, after which the samples were flashfrozen in liquid nitrogen and kept at $-80{ }^{\circ} \mathrm{C}$. Frozen material was ground in liquid nitrogen with a mortar and pestle. The resultant powder was homogenised with $90 \%$ methanol. The homogenate was centrifuged at $10,000 \times \mathrm{g}$ for $30 \mathrm{~min}$, and the soluble fraction was isolated and lyophilised. The UV absorption spectra were obtained using a Shimadzu spectrophotometer $(\lambda=495 \mathrm{~nm})$. The antifungal activity of isolated compounds was visualised employing the bioassay system described below.
Hippeastrum scale phytoalexin production after Peyronellaea curtisii infection

The effect of fungal strains on the ability of wounded scales to synthesise PA was investigated. Liquid cultures of fungal strains were prepared according to Hrynkiewicz et al. (2010). The Hippeastrum scales were prepared as described above. Scales were placed on sterile Petri dishes, and $5 \mathrm{ml}$ of fungal inoculum (strains P2, P4, P6, P10, P80) was added. Material was incubated inside a growth chamber at $25^{\circ} \mathrm{C}$ for 3 days. PA was isolated and identified for further analysis as described above.

Antifungal bioassay of phytoalexin

The antifungal bioassays of Hippeastrum-derived PA were conducted in vitro. Three concentrations of $\mathrm{PA}$, which were isolated from 1,2 or $5 \mathrm{~g}$ of tissue (PA1, PA2 and PA3, respectively), were assayed. Lyophilised fractions were dissolved in $1 \mathrm{ml}$ of $50 \%$ ethanol and then added to sterile PDA medium, stirred, and poured into Petri dishes (15 $\mathrm{ml}$ per plate). Plugs (10 $\mathrm{mm}$ in diam.) were taken from 7-day-old cultures of $P$. curtisii and placed in the middle of Petri dishes containing medium supplemented with the tested compound. The control plates contained the culture growing on pure PDA, with ethanol as above but lacking PA. Five Petri dishes were used as an experimental unit, and the trial was repeated three times. The incubation was conducted at $25{ }^{\circ} \mathrm{C}$ in the dark. After 3 and 7 days of incubation, the diameter of the fungal colonies was measured in two perpendicular directions.

Statistical analyses

One- and two-factor analysis of variance (ANOVA) and Newman-Keuls multiple range test ( $p \leq 0.05$; for comparison of means) were used to compare enzymatic activity and phytoalexin production. The comparison of the effect of PA on fungal growth was carried out using a three-factor analysis of variance and Newman-Keuls multiple range test ( $p \leq 0.05$; for comparison of means). All statistical analysis were performed using Statistica for Windows, release 5.1 (1996; statSoft, Tulsa, OK, USA). 


\section{Results}

Morphology of the studied strains

Figure 1 shows the differences in colour of the fungal colonies grown on OA and MEA after 8 and 20 days after inoculation. All investigated strains (P2, P4, P6, P10 and $\mathrm{P} 80)$ share the similar pattern and rate of growth, as well as the range of colours of 14-20 day old colonies.

Culture characteristics Colonies on OA fast growing, $75-85 \mathrm{~mm}$ diam after $8 \mathrm{~d}$, margin regular. Aerial mycelium dense, white/amber becoming greyish green/olivaceous/smoky grey, fluffy or floccose to woolly. Immersed mycelium hyaline to greenish grey near the colony centre, dark greyish olivaceous in $20 \mathrm{~d}$ cultures; reverse pale greyish to iron grey/greyish black in $20 \mathrm{~d}$ cultures. Colonies on MEA also fast growing $65-80 \mathrm{~mm}$ diam. After $8 \mathrm{~d}$, margin regular. Immersed mycelium olivaceous/ochraceous, in young colonies the aerial mycelium often honey with olivaceous ting at the margin, later completely covered by a densely floccose mycelial mat, which is greyish olivaceous to smoky grey in $20 \mathrm{~d}$ cultures; reverse reddish brown becoming primrose brown/black, with honey olivaceous/buff olivaceous margin in older colonies.

Those phenotypic traits allow to classify (with a caution) all studied strains in Peyronellaea curtisii (Berk.) Aveskamp, Gruyter \& Verkley [syn. Phoma narcissi (Aderh.) Boerema, Gruyter \& Noordel.], pathogen specific to Narcissus, Hippeastrum and other Amaryllidaceae (Boerema et al. 2004). However, the appearance of young $8 \mathrm{~d}$ (and $5 \mathrm{~d}$, not shown) colonies, growth rate on PDA, as well as micromorphological features significantly varied among the strains. The differences, including chlamydospore type, conidial size and septation (Fig. 2), indicate that the strains may represent species belonging to different sections of Phoma as characterized by Boerema and co-workers (2004). The supposed species were Boeremia exigua (Desm.) Aveskamp, Gruyter \& Verkley (strain P4) and Phoma sp. sect. Plenodomus (strain P2). The descriptions (given below) include mainly the features differentiating the strains.

Strain P2 No chlamydospores and pycnidia were formed, but a few thick-walled, young pycnosclerotia were observed in 90-days-old culture on PDA. On OA and MEA the fungus formed dark reddish brown hyphal
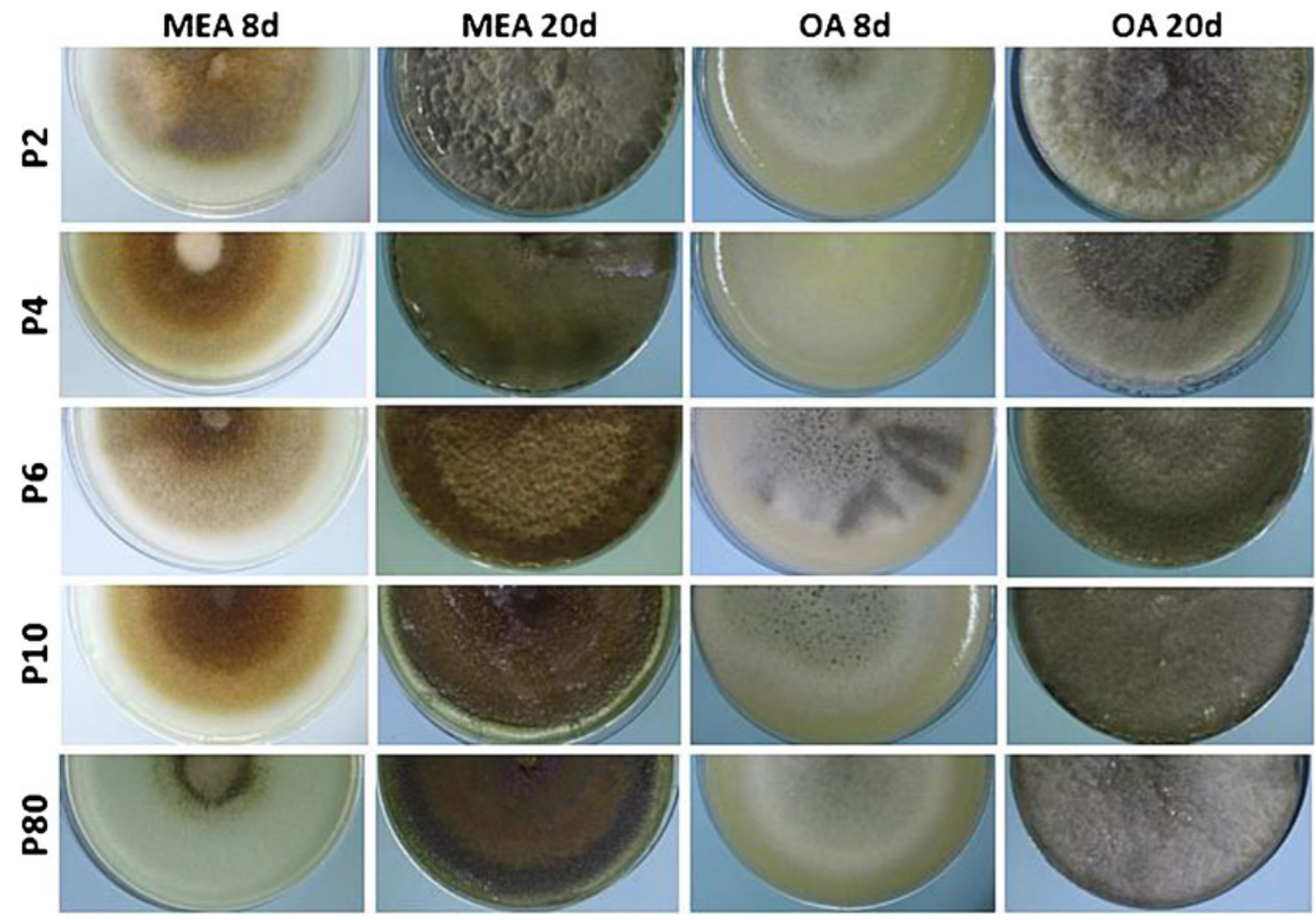

Fig. 1 The morphology of colony of five P. curtisii strains on OA and MEA 
Fig. 2 The morpho-anatomical presentation of $P$. curtisii mycelial structures. Abbreviations: MC: thick-walled, dark, multicellular chlamydospore. UC: irregular chain of unicellular chlamydospores, DD: hemispherical droplet-like deposits at hyphal surface
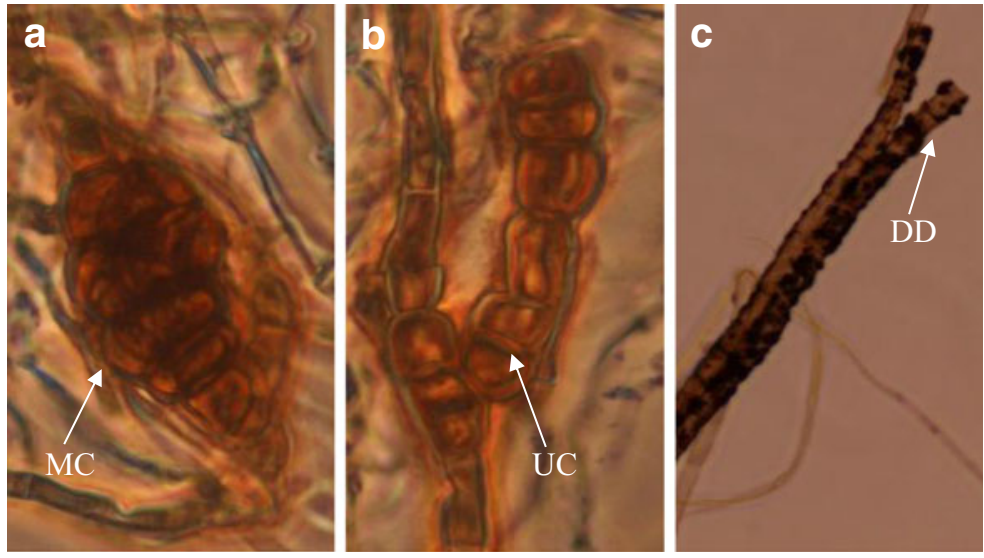

strands composed of parallel, thick-walled hyphae. Hyphae in old colonies (60 d on MEA and OA, and $90 \mathrm{~d}$ on PDA) had hemisphaerical droplet-like deposits resembling groupings of irregular crystals (Fig. 2c). Application of $\mathrm{NaOH}$ resulted with non-specific reddish discoloration after $3 \mathrm{~min}$. Based on these traits, strain could be classified in the Phoma sect. Plenodomus (Preuss) Boerema, Kesteren \& Loer. (Boerema et al. 2004). However, characters of in vivo appearance (not available in this study) are necessary for confirmation and identification to the species level.

Strain P4 Pycnidia ca. $160 \mu \mathrm{m}$ diam. on OA, forming dense layer on the medium or submerged, globose, solitary to confluent, wall pseudoparenchymatous, often with hyphal outgrows, pycnidial ostiolum single, lined internally with papillate hyaline cells. Conidia 1-3-septate (1-celled 2-2.5 × 5-7.5 $\mu \mathrm{m}, 2$-celled, ascochytoid, 2.5-3.75 × 7.5-12.5 $\mu \mathrm{m}, 3-4$-celled $3.75 \times 12.5-$ $15 \mu \mathrm{m}$, not constricted at the septa, they constitute 60 $70 \%$ of conidia in $20 \mathrm{~d}$ cultures). Chlamydospores unicellular, globose to irregular, in chains, submerged in the medium. Application of $\mathrm{NaOH}$ did not have any effect. Such type of ostiolum and conidial septation is observed in sect. Phyllostictoides Žerbele ex Boerema, e.g. the type species Boeremia exigua although it does not produce multicellular chlamydospores.

Strain P6 and P10 Features of pycnidia on OA, spores [1-2-celled, guttulate, $2.5 \times 5(-7.5) \mu \mathrm{m}$, 2-celled scarce] and chlamydospores (irregular, botryoiddictyosporous, solitary or in short chains) are typical for Peyronellaea curtisii. NaOH test negative. In addition, hyphae of P10 strain had hemisphaerical dropletlike deposits.
Strain P80 Pycnidia solitary and confluent on OA, submerged, subglobose and irregular, 150-187.5 $\mu \mathrm{m}$ diam., wall pseudoparenchymatous, 1-3-ostiollate. Conidial matrix buff/white; conidia 1-2(-4)-celled, some septa oblique. These conidial types, including the dimensions, are very similar to those described in $\mathrm{P} 4$ strain. Chlamydospores of two types: unicellular, in chains up to $15-20$ cells, and multicellular, irregular, botryoiddictyosporous, mainly solitary, up to $37.5 \times 62.5 \mu \mathrm{m}$. $\mathrm{NaOH}$ test negative. Hyphae with hemispherical droplet-like deposits.

\section{Molecular identification}

The molecular identification of five fungal strains was performed using an analysis of the ACT (Fig. 3) and TUB (Fig. 4) genes. In case of both analysed fragments phylogenetic analysis revealed a most close similarity to Peyronellaea curtisii strains. Phylogenetic analysis of actin-sequences recognized analyzed strains as the closest relative to four $P$. curtisii strains with Acc. No: FJ426931, FJ426930, FJ426928 and FJ426929 (Aveskamp et al. 2009), isolated from Sprekelia sp., Hippeastrum sp., Nerine sp. and Ismene sp., respectively. The sequences formed with actin genes of five analyzed strains a subclade with 99 bootstrap value (Fig. 3). TUB sequences of five fungal strains formed a clade with high bootstrap support (value 88) within the same group of P. curtisii strains (Acc No: FJ427151, FJ427150, FJ427148, FJ427149; Aveskamp et al. 2009) as in case of ACT analysis (Fig. 4).

Metabolic activity of P. curtisii strains

The enzymatic activity (amylolytic, pectolytic and cellulolytic) of the strains P2, P4, P6, P10 and P80 was 


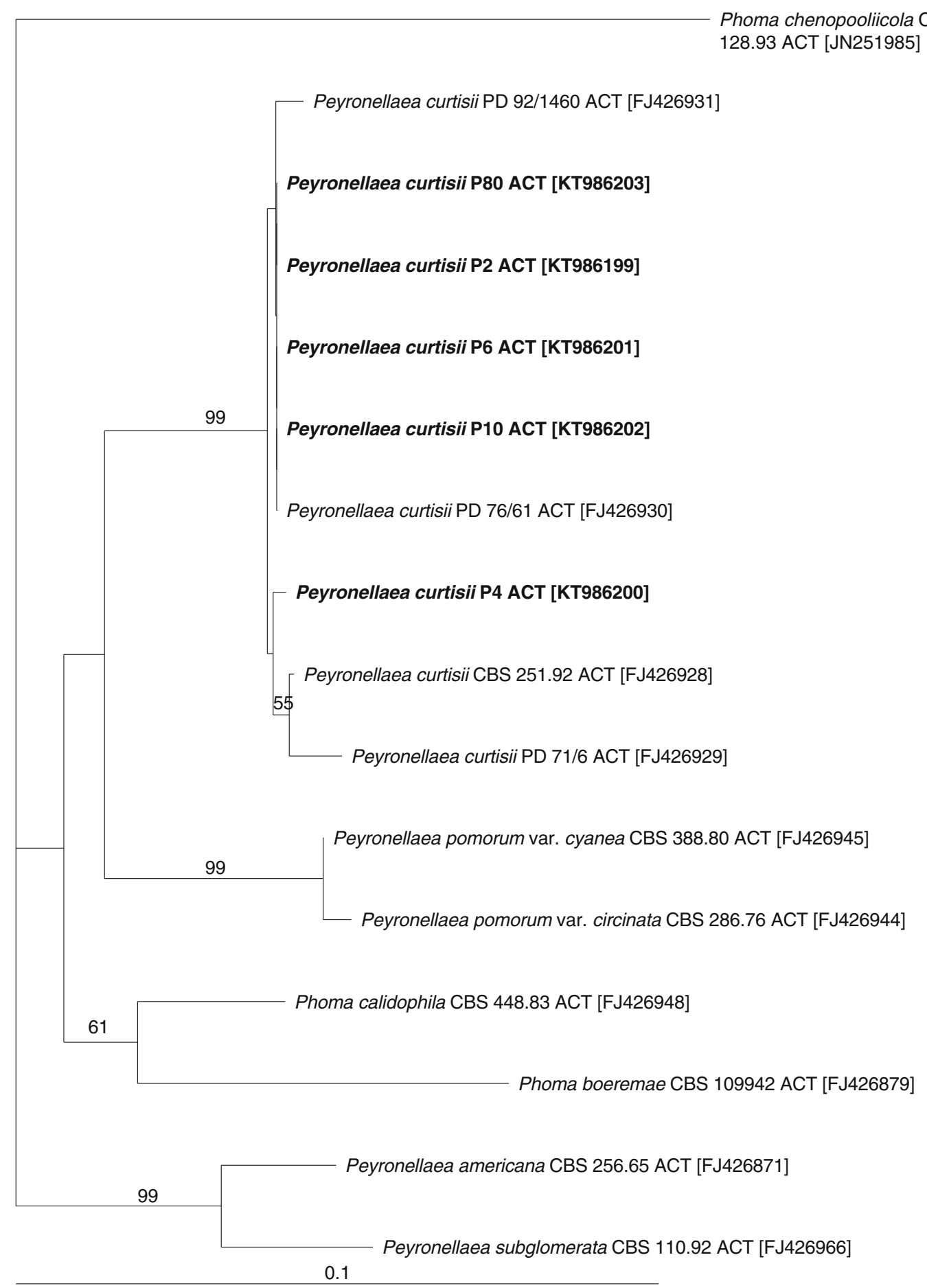

Fig. 3 Phylogenetic relationships of the five $P$. curtisii strains included in this study based on ACT sequences

determined by measuring their growth on medium supplemented with either starch, pectin or carboxymethylcellulose (CMC) (Table 1). The coefficient activity $\left(\mathrm{W}_{\mathrm{act}}\right)$ values obtained for amylolytic activity ranged from 0.47 to 0.88 . P2 displayed the highest capacity for hydrolysing starch, and strains P4 and P10 had the lowest activity. Strains P6 and P80 did not differ in their amylolytic activity, which was significantly lower than 


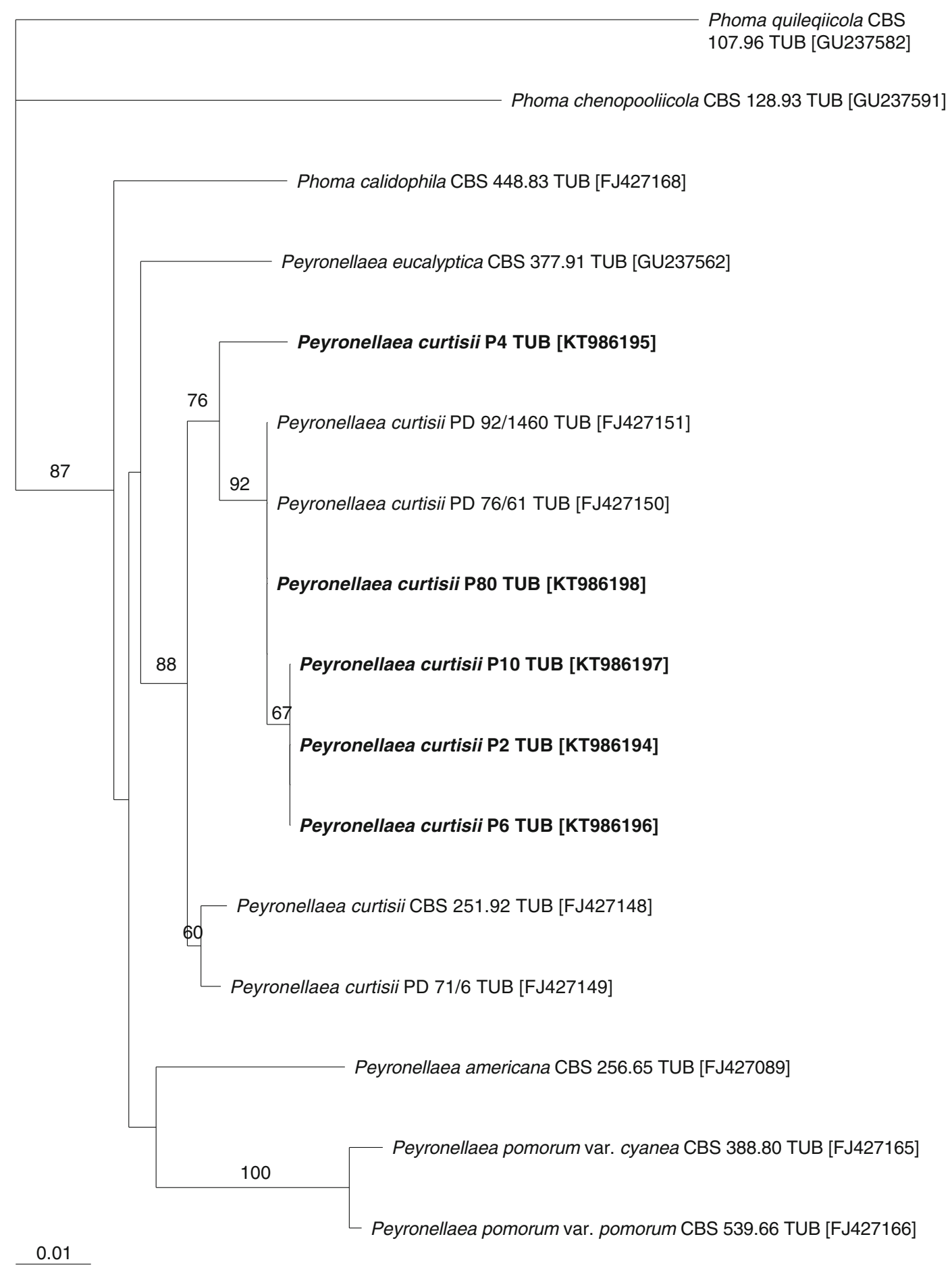

Fig. 4 Phylogenetic relationships of the five $P$. curtisii strains included in this study based on TUB sequences

that of strains P2 but significantly higher than strains P4 and $\mathrm{P} 10$. The $\mathrm{W}_{\text {act }}$ values for pectolytic activity ranged from 1.09-1.61. The highest activity was observed for strain P80, and the lowest was observed for strain P2.
The other three strains (P4, P6 and P10) did not differ in their activity and showed a significantly higher value than $\mathrm{P} 2$, and a lower $\mathrm{W}_{\text {act }}$ compared with $\mathrm{P} 80$. The $\mathrm{W}_{\text {act }}$ values for cellulolytic activity ranged from 0.83 to 1.21 . 
Similar to amylolytic activity, strain P2 showed the highest cellulolytic activity, and the lowest activity was observed for strains P4 and P10. Strains P6 and P80 did not differ significantly from one another and showed a significantly lower activity than the strain P2 and higher activity than $\mathrm{P} 4$ and $\mathrm{P} 10$.

Based on the results presented in Table 1, a correlation between the hydrolysis of starch and CMC was observed in the strains investigated. Strain P2 was characterised by the highest, and strains P4 and P10 the lowest, activity of both amylolytic and cellulolytic activity. Furthermore, strains with low amylolytic and cellulolytic activity had high pectolytic activity. Statistical analysis confirmed the significant correlation of amylolytic and cellulolytic activity $(r=0.95)$ (Fig. 6).

Table 2 shows the results of two-way analysis of variance (ANOVA2) for the five fungal strains and their enzymatic activities based on the $\mathrm{W}_{\text {act }}$ values. The analysis showed a statistically significant effect of all of the tested sources of variation: strain, enzymatic activity and interaction strain $\mathrm{x}$ enzymatic activity. The strain effect was most significant for strain P80 and least significant for strain P10. Generally, the activity of all of the tested strains of $P$. curtisii increased in the following order: $\mathrm{P} 80<\mathrm{P} 2<\mathrm{P} 6 \leq \mathrm{P} 4 \leq \mathrm{P} 10$. The hydrolysis of pectin had the highest effect on the enzymatic activity, whereas the hydrolysis of starch had the lowest.

Table 1 Enzymatic activity of $P$. curtisii strains expressed as activity coefficient $\left(\mathrm{W}_{\mathrm{act}}\right)$ (ANOVA)

\begin{tabular}{|c|c|c|c|c|}
\hline & & \multicolumn{3}{|c|}{ Activity coefficient $\left(\mathrm{W}_{\mathrm{act}}\right)$} \\
\hline & & amylolytic & pectolytic & cellulolytic \\
\hline \multirow[t]{5}{*}{ P. curtisii } & $\mathrm{P} 2$ & $\begin{array}{l}0,88 \mathrm{c} \\
\pm 0058\end{array}$ & $\begin{array}{l}1,09 \mathrm{a} \\
\pm 0028\end{array}$ & $\begin{array}{l}1,21 \mathrm{c} \\
\pm 0041\end{array}$ \\
\hline & $\mathrm{P} 4$ & $\begin{array}{l}0,53 \mathrm{a} \\
\pm 0120\end{array}$ & $\begin{array}{l}1,52 \mathrm{~b} \\
\pm 0100\end{array}$ & $\begin{array}{l}0,83 \mathrm{a} \\
\pm 0020\end{array}$ \\
\hline & P6 & $\begin{array}{l}0,64 \mathrm{~b} \\
\pm 0100\end{array}$ & $\begin{array}{l}1,47 \mathrm{~b} \\
\pm 0080\end{array}$ & $\begin{array}{l}0,88 \mathrm{~b} \\
\pm 0050\end{array}$ \\
\hline & P10 & $\begin{array}{l}0,47 \mathrm{a} \\
\pm 0077\end{array}$ & $\begin{array}{l}1,53 \mathrm{~b} \\
\pm 0050\end{array}$ & $\begin{array}{l}0,83 \mathrm{a} \\
\pm 0040\end{array}$ \\
\hline & P80 & $\begin{array}{l}0,69 \mathrm{~b} \\
\pm 0133\end{array}$ & $\begin{array}{l}1,61 \mathrm{c} \\
\pm 0042\end{array}$ & $\begin{array}{l}1,05 \mathrm{~b} \\
\pm 0050\end{array}$ \\
\hline
\end{tabular}

Data represent the mean of nine replicates \pm SD. Mean values within the given column marked with the same letter do not differ significantly $(p<0.05)$
Elicitation of phytoalexin production in Hippeastrum scales

Bulbs of Hippeastrum infected by Phoma/Peyronellaea fungi or mechanically wounded produce red pigment on the surface of injured tissues (Saniewska and Budzianowski 1997). However, our research has shown that the reaction strength (intensity) varies depending on the type of stimulus. Just 2 days after mechanical injuries, intensive reddish coloration develops on scales (Fig. 5). After fungal infection PA biosynthesis is suppressed, particularly for strains $\mathrm{P} 2$, P4 and P80 (17, 25, $18 \%$, respectively, relative to those observed in injured plants).

Antifungal bioassay of phytoalexin

The red compound extracted from bulb applied to the PDA medium limited or completely inhibited the mycelium growth of $P$. curtisii strains at all concentrations (Fig. 6, Table 3). It should be noted that in all cases, the mycelium discs that were incubated for 3 or 7 days on PDA supplemented with the highest PA level and subsequently transferred to clean PDA did not start to grow. However, in case of the medium PA concentration, only P2 and P80 did not start to grow. The rest of the strains grew, but only slightly Fig. 7.

\section{Discussion}

The extensive analysis of Phoma s.l. taxonomy dates to the 1960s and has resulted in detailed descriptions of tens of pathogenic species, with a particular emphasis on their morphological and cultural characteristics (Boerema et al. 2004). However, the in vitro morphological characteristics of Phoma s.l. fungi are highly variable, resulting in their uncertain identifications and descriptions (Aveskamp et al. 2010). The currently used identification procedures are based on the similarity of the queried DNA sequences to those found in public DNA libraries (Hyde and Soytong 2007). However, many such libraries may contain mistakenly identified sequences and this can increase the likelihood of misidentification of fungi within the coelomycetes, particularly when studies are conducted based only on molecular similarities (Nilsson et al. 2006). 
Table 2 Interaction of two factors: (1) P. curtisii strain (P2, P4, P6, P10, P80) and (2) enzymatic activity (amylolytic, pectolytic, cellulolytic) on the coefficient activity $\left(\mathrm{W}_{\text {act }}\right)$ (ANOVA2)

$* p \leq 0.05, \mathrm{MS}-$ mean square, ?F - ratio of MS (effect) to MS (error). Values within the given row marked with the same letter do not differ significantly $(p<0.05)$

\begin{tabular}{|c|c|c|c|c|c|}
\hline Source of variation & MS Effect & $\mathrm{F}$ & P level & & \\
\hline (1) Strain & 0,1401 & 25,63 & $0,0000 *$ & & \\
\hline (2) Enzymatic activity & 7,3788 & 1349,56 & $0,0000 *$ & & \\
\hline$(1) \times(2)$ & 0,3571 & 65,32 & $0,0000 *$ & & \\
\hline Error & 0,0055 & - & - & & \\
\hline \multicolumn{6}{|c|}{ Newman-Keuls post-hoc comparison } \\
\hline (1) P P. curtisii: & $\mathrm{P} 2$ & P4 & P6 & $\mathrm{P} 10$ & P80 \\
\hline (2) Enzymatic activity: & $\begin{array}{l}1,0598 \mathrm{c} \\
\text { amylolytic } \\
0,6414 \mathrm{a}\end{array}$ & $0,9614 \mathrm{ab}$ & $\begin{array}{l}0,9971 \mathrm{~b} \\
\text { pectolytic } \\
1,4455 \mathrm{c}\end{array}$ & $\begin{array}{l}0,9426 \mathrm{a} \\
\text { cellulolytic } \\
0,9596 \mathrm{~b}\end{array}$ & $1,1165 \mathrm{~d}$ \\
\hline
\end{tabular}

The colony morphology and microscopic structures of the five strains analysed in this work confirmed (with a caution) their membership in the Peyronellaea curtisii. As recently emphasized (e.g., Aveskamp et al. 2010; Rai et al. 2014), a multi-gene approach combined with morphological and physiological traits (secondary metabolites, isozymes) is necessary to solve the phylogeny of Phoma s.l., including Peyronellaea.
Researchers (de Gruyter et al. 2009; Aveskamp et al. 2009a, 2009b, 2010) have proposed a number of genes as potentially useful standard marker genes for a given species of Phoma and allied genera, e.g., 28S nrDNA (Large Subunit - LSU), the Internal Transcribed Spacer regions 1 and 2 and 5.8S nrDNA (ITS), 18S nrDNA (Small Subunit - SSU), actin (ACT) and part of the $\beta$ tubulin (TUB) gene region. The analysis of the ITS and LSU genes from the 5 Peyronellaea strains tested in this cellulolytic $=0,31187+1,0108$ * amylo

Correlation: $r=0,94790$
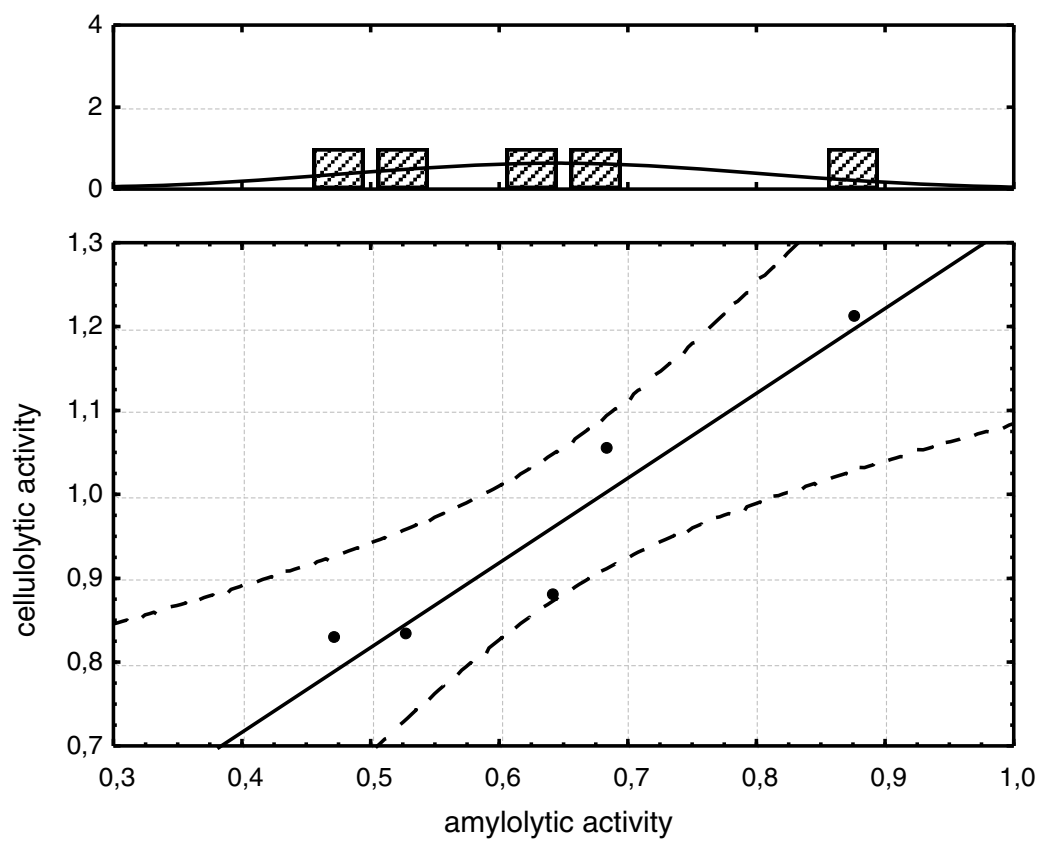

amylolytic activity
$\mathrm{X:} \begin{gathered}\text { amylo } \\ \mathrm{N}=5\end{gathered}$

$\mathrm{N}=5$
$\mathrm{Mean}=0,641419$ Std.Dv. $=0,15711$ Max. $=0,877449$
Min. $=0,472631$

Y: cellulolytic

$\mathrm{N}=5$

Mean $=0,960222$ Std.Dv. $=0,167537$
Max. $=1,210000$ Min. $=0,827778$

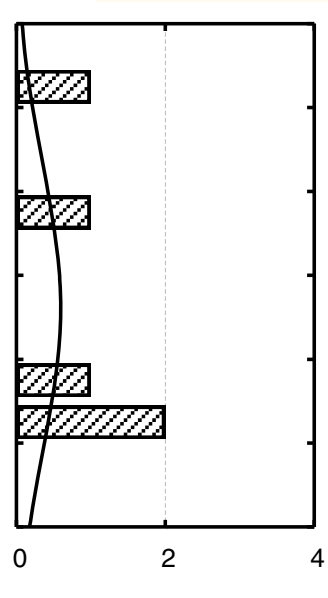

$95 \%$ confidence

Fig. 5 Correlation of enzymatic activities of the five $P$. curtisii strains included in this study 
Fig. 6 Effect of concentration of phytoalexin (Ctr, FA1, FA2, FA3) and time of cultivation ( 3 and 5 days) on the growth of $P$. curtisii strains: P2, P4, P6, P10, P80

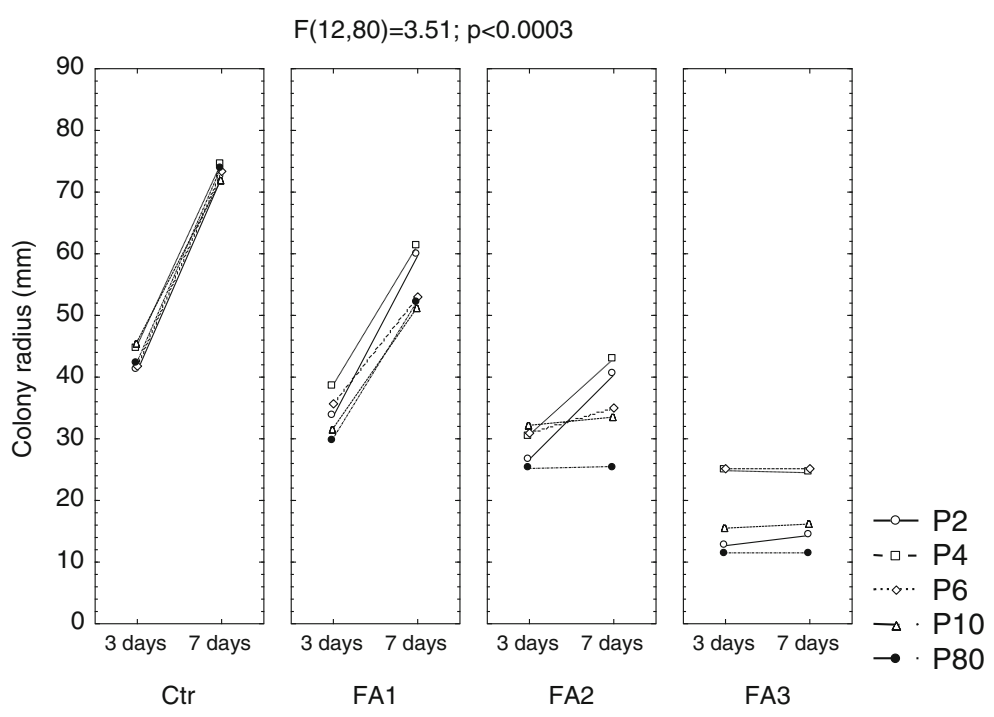

work confirmed the previously mentioned difficulties in the identification and taxonomy of Phoma s.l. pathogens and did not allow the unambiguous identification of the tested strains. Analysis of ACT and TUB sequences revealed clear similarity of strains analysed in this work to P. narcissi, recently renamed as Peyronellaea curtisii, which suggests the best specificity of above regions for identification of Phoma s.l. fungi.

Aveskamp et al. (2010) suggested that the use of molecular analysis only, without using additional morphological characterisation, might fail to resolve species identities that could be understood by observing physiological properties. Boerema et al. (2004) used standardised conditions to define different species according to stable morphological characteristics. Other criteria, such as host-plant or substratum, were mostly abandoned. Nevertheless, several physiological characters seem to be helpful in the delimitation of species within Phoma/Peyronellaea spp. e.g., the utilisation of different carbon sources, the activity of selected enzymes or pigment production (Monte et al. 1991; Rai et al. 2014). Thus, to some extent, identification must be
Table 3 Interaction of three factors: (1) time of cultivation (3 and 7 days), (2) $P$. curtisii strain (P2, P4, P6, P10, P80) and (3) concentration of phytoalexin (Ctr, FA1, FA2, FA5) on the growth of different strains (ANOVA3)
$* p \leq 0.05, \mathrm{MS}-$ mean square, $\mathrm{F}$ ratio of MS (effect) to MS (error). Values within the given row marked with the same letter do not differ significantly $(p<0.05)$

\begin{tabular}{|c|c|c|c|c|c|}
\hline Source of variation & MS Effect & Parameter F & p-level & & \\
\hline (1) Time & 6424.03 & 1440.91 & $0,00,000^{*}$ & & \\
\hline (2) Strain & 260.05 & 58.33 & $0,00,000^{*}$ & & \\
\hline (3) FA concentration & 8752.46 & 1963.17 & $0,00,000^{*}$ & & \\
\hline$(1) \times(2)$ & 36.47 & 8.18 & $0,00,001 *$ & & \\
\hline$(1) \times(3)$ & 1395.92 & 313.10 & $0,00,000^{*}$ & & \\
\hline$(2) \times(3)$ & 60.70 & 13.62 & $0,00,000^{*}$ & & \\
\hline$(1) \times(2) \times(3)$ & 15.64 & 3.51 & $0,00,035^{*}$ & & \\
\hline Error & 4.46 & - & - & & \\
\hline \multicolumn{6}{|c|}{ Newman-Keuls post-hoc comparison } \\
\hline (1) Time: & $\begin{array}{l}3 \text { days } \\
30.8667 a\end{array}$ & & $\begin{array}{l}7 \text { days } \\
45.5000 \mathrm{~b}\end{array}$ & & \\
\hline \multirow[t]{2}{*}{ (2) P. curtisii: } & $\mathrm{P} 2$ & P4 & P6 & $\mathrm{P} 10$ & P80 \\
\hline & $37.5833 b$ & $42.5417 \mathrm{~d}$ & $40.0000 \mathrm{c}$ & $37.0000 \mathrm{~b}$ & $33.7917 \mathrm{a}$ \\
\hline \multirow[t]{2}{*}{ (3) PA concentration: } & $\mathrm{Ctr}$ & FA1 & FA2 & FA3 & \\
\hline & $58.0000 \mathrm{~d}$ & $44.5333 \mathrm{c}$ & $32.1667 b$ & $18.0333 \mathrm{a}$ & \\
\hline
\end{tabular}




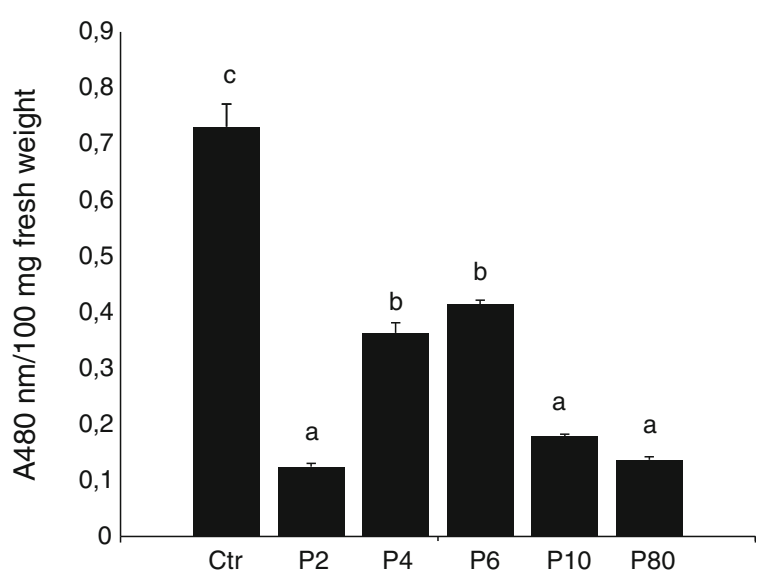

Fig. 7 Effect of P. curtisii strains P2, P4, P6, P10, P80 on the rate of synthesis of phytoalexin by damaged and infected bulbs of Hippeastrum plant

performed based on the physiological and pathogenic properties of fungal species. The presented work shows, for the first time, a characterisation of the enzymatic activity of $P$. curtisii strains.

In this study, three enzymatic activities were used (amylolytic, pectolytic and cellulolytic), which helped determine an average level of activity for $P$. curtisii fungi. The variable enzymatic activity also helped differentiate the five tested strains. The pectolytic activity assay proved to be the most useful for this purpose. The assessment of starch and cellulose hydrolysis also resulted in statistically significant differences among the tested strains. The ability to produce pectolytic and cellulolytic enzymes is widespread among plant pathogenic microorganisms (Mańka 1981) and saprophytes (Strzelczyk and Szpotański 1989). The study of enzymatic activity, including those of pectinases and cellulases, conducted by Lyr (1963) on mycorrhizal, pathogenic and saprophytic soil fungi, showed that this activity was significantly higher in pathogenic and saprophytic fungi than in mycorrhizal ones. Therefore, it may be concluded that specific enzymatic activity can indicate the pathogenicity of particular fungal strains. In this study, the highest cellulolytic and amylolytic activity was found in strains that had the lowest pectolytic activity. Some authors have suggested that the enzymatic activity of fungi may not be observed under certain conditions, such as inadequate substrate, $\mathrm{pH}$, and other components of the growth medium (Romanowska et al. 2004). It has been reported that carbon sources differ in their availability to different microorganisms. For example, in studies on cellulolytic activity, CMC (carboxymethylcellulose) or cellulose powder are commonly used as a carbon source. It has been shown that CMC was a more readily available carbon source for Cantharellus cibarius (Dahm et al. 1999). For pectolytic activity, different pectin compounds may be used. Brumano et al. (1993) revealed a correlation between pectolytic activity level and the type of the carbon source for Penicillium griseoroseum. In the present study, we used pectin as the source of carbon to test pectolytic activity. In this work, $P$. curtisii strains were tested using a narrow spectrum of physiological properties, which provides only an overview of their biochemical characteristic. Nevertheless, the enzymatic activity analysis allowed us to differentiate among strains, which was supported by morphological features, but could not be observed using molecular studies.

Plants recognise invading pathogens and respond biochemically to prevent invasion or inhibit colonisation, e.g., by synthesising phytoalexins. This work was conducted to differentiate and select $P$. curtisii strains that are sensitive or tolerant to phytoalexin isolated from Hippeastrum and to determine the relationships between phytoalexin production and fungal pathogenicity. Only one preliminary report concerning this topic was published a few years ago and revealed that various mechanically wounded Hippeastrum organs produce a mixture of orange-coloured flavans that can be oxidised to red-coloured isoflavone dimers (Wink and Lehmann 1996). Such substances can prevent the penetration of injured tissues by P. curtisii (= Phoma narcissi), Botrytis cinerea and Fusarium oxysporum (Saniewska and Budzianowski 1997).

In our survey, five strains identified as $P$. curtisii, were tested for tolerance to phytoalexin from Hippeastrum. The strains P6, P10 and P80 metabolised PA very poorly, but strains $\mathrm{P} 2$ and $\mathrm{P} 4$ were able to metabolise PA almost completely at lower concentration. The growth of all strains was completely inhibited by PA from $5 \mathrm{~g}$ of fresh tissue, suggesting that they were unable to deactivate PA at higher concentrations.

It is well established that some plant pathogenic fungi are tolerant to their hosts' phytoalexin. Such strains are often able to detoxify the phytoalexins to which they are tolerant (VanEtten et al. 1989). It was revealed that a strain of the potato pathogen Gibberella pulicaris/ Fusarium sambucinum rapidly metabolised added lubimin (Gardner et al. 1988). Pea pathogens are very tolerant to the pea phytoalexin (pisatin) and are known to detoxify it (Van Etten et al. 1989). The PA tolerance 
and detoxification process has been studied in detail using the pea pathogen Nectria haematococca, which demethylate spisatin to a nontoxic product.

Tolerance of the strains in this study to PA correlated with lower PA levels when grown in Hippeastrum scales. Phytoalexin concentration was lower in tissue inoculated with strains P2, P80 and P10 compared with scales inoculated with strains P4 and P6. A similar correlation was observed for lubimin from potato infected with Fusarium (Desjardins and Plattner 1989). Overall, the results of this work suggest that each strain of $P$. curtisii appears to have a unique potential to protect itself from Hippeastrum-produced PA. Analysis of pathogenic activity based on enzymatic properties helped differentiate strains and revealed a significant correlation of cellulolytic activity with the level of synthesised amylolytic enzymes. Our results have revealed that phytoalexin production is an important defence response in Hippeastrum $\times$ hybridum against $P$. curtisii. Because strains with the highest enzymatic activity (P2 and P80) significantly decreased the levels of phytoalexin in Hippeastrum bulbs, we suggest that the more pathogenic strains may mitigate plant resistance by metabolising phytoalexin.

Acknowledgments This investigation was done in frame of COST action FA1103 and financially supported by the grants from the National Science Centre (Poland) (2011/03/B/NZ9/00752) and University of Lodz grant (2014). The manuscript benefited from critical comments of two anonymous reviewers.

Open Access This article is distributed under the terms of the Creative Commons Attribution 4.0 International License (http:// creativecommons.org/licenses/by/4.0/), which permits unrestricted use, distribution, and reproduction in any medium, provided you give appropriate credit to the original author(s) and the source, provide a link to the Creative Commons license, and indicate if changes were made.

\section{References}

Altschul, S. F., Gish, W., Miller, W., Myers, E. W., \& Lipman, D. J. (1990). Basic local alignment search tool. Journal of Molecular Biology, 215, 403-410.

Armstrong, K. F., \& Ball, S. L. (2005). DNA barcodes for biosecurity: invasive species identification. Philosophical Transactions of the Royal Society of London B, 360, 1813-1823.

Aveskamp, M. M., de Gruyter, J., \& Crous, P. W. (2008). Biology and recent developments in the systematics of Phoma, a complex genus of major quarantine significance. Fungal Diversity, 31, 1-18.
Aveskamp, M. M., Verkley, G. J. M., de Gruyter, J., Murace, M. A., Perello, A., Woundenberg, J. H. C., Groenewald, J. Z., \& Crous, P. W. (2009a). DNA phylogeny reveals polyphyly of Phoma section Peyronellaea and multiple taxonomic novelties. Mycologia, 101(3), 363-382.

Aveskamp, M. M., Woudenberg, J. H. C., de Gruyter, J., Turco, E., Groenewald, J. Z., \& Crous, P. W. (2009b). Development of taxon-specific sequence characterized amplified region (SCAR) markers based on Actin sequences and DNA amplification fingerprinting (DAF): a case study in the Phoma exigua species complex. Molecular Plant Pathology, 10, 403-414.

Aveskamp, M. M., de Gruyter, J., Woudenberg, J. H. C., Verkley, G. J. M., \& Crous, P. W. (2010). Highlights of the didymellaceae: a polyphasic approach to characterise phoma and related pleosporalean genera. Studies in Mycology, $65,1-60$.

Boerema, G. H., de Gruyter, J., Noordeloos, M. E., \& Hamers, M. E. C. (2004). Phoma identification manual. Differentiation of specific and infra-specific taxa in culture. Wallingford, UK: CABI Publishing.

Brumano, M. H. N., Coehlo, J. L. C., Araujo, E. F., \& de Silva, D. O. (1993). Pectin lyase activity of Penicillium griseoroseum related to degumming of ramie. Revista de Microbiologia, 24, 175-178.

Carbone, I., \& Kohn, L. M. (1999). A method for designing primer sets for speciation studies in filamentous ascomycetes. Mycologia, 91, 553-556.

Crous, P. W., et al. (2013). Fungal planet description sheets: 154 213. Persoonia, 31, 188-296.

Dahm, H., Strzelczyk, E., Pachlewski, R., \& Różycki, H. (1999). Cellulase, pectinase and proteinase production by the ectomycorrhizal fungus Cantharellus cibarius Fr. Pedobiologia, 43, 193-205.

Delserone, L. M., McCluskey, K., Matthews, D. E., \& VanEtten, H. D. (1999). Pisatin demethylation by fungal pathogens and nonpathogens of pea: association with pisatin tolerance and virulence. Physiological and Molecular Plant Pathology, 55, 317-326.

Desjardins, A. E., \& Plattner, R. D. (1989). Trichothecene toxin production by strains of Gibberella pulicaris (fusarium sambucinum) in liquid culture and in potato tubers. Journal of Agricultural and Food Chemistry, 37, 388-392.

Dixon, R. A. (2001). Natural products and plant disease resistance. Nature, 411(6839), 843-847.

Felsenstein, J. (1985). Confidence limits on phylogenies: an approach using the bootstrap. Evolution, 39, 783-791.

Gardner, H. W., Desjardins, A. E., Weisleder, D., \& Plattne, R. D. (1988). Biotransformation of the potato phytoalexin, lubimin, by gibberella pulicaris. Identification of major products. Biochimica Biophysica Acta, 966, 347-356.

Gibson, T., \& Gordon, R. E. (1974). Bacillus. In R. E. Buchanan, \& N. E. Gibbons (Eds.), Berge-y's manual of determinative bacteriology (8th ed., pp. 529-550). Baltimore: Williams \& Wilkins.

de Gruyter, J., Aveskamp, M. M., Woudenberg, J. H., Verkley, G. J., Groenewald, J. Z., \& Crous, P. W. (2009). Molecular phylogeny of Phoma and allied anamorph genera: towards a reclassification of the phoma complex. Mycological Research, 113, 508-519. 
Hasegawa, M., Mitsuhara, I., Seo, S., Imai, T., Koga, J., Okada, K., Yamane, H., \& Ohashi, Y. (2010). Phytoalexin accumulation in the interaction between rice and the blast fungus. Molecular Plant-Microbe Interactions, 23, 1000-1011.

Horbach, R., Navarro-Quesada, A. R., Knogge, W., \& Deising, H. B. (2011). When and how to kill a plant cell: infection strategies of plant pathogenic fungi. Journal of Plant Physiology, 168, 51-62.

Hrazdina, G., Borejsza-Wysocki, W., \& Lester, C. (1997). Phytoalexin production in an apple cultivar resistant to Venturia inaequalis. Phytopathology, 87, 868-876.

Hrynkiewicz, K., Ciesielska, A., Haug, I., \& Baum, C. (2010). Conditionality of ectomycorrhiza formation and willow growth promotion by associated bacteria: role of microbial metabolites and use of $\mathrm{C}$ sources. Biology and Fertility of Soils, 46, 139-150.

Hyde, K. D., \& Soytong, K. (2007). Understanding microfungal diversity: a critique. Cryptogamie. Mycologie, 28, 281-289.

Index Fungorum. 2015. Retrieved on 24th Aug. 2015 at www. indexfungorum.org

Irinyi, L., Kövics, G. J., \& Sándor, E. (2009). Taxonomical reevaluation of Phoma-like soybean pathogenic fungi. Mycological Research, 113, 249-260.

Kimura, M. (1980). A simple method for estimating evolutionary rate of base substitutions through comparative studies of nucleotide sequences. Journal of Molecular Evolution, 16, $111-120$

Kuć, J. (1982). Phytoalexins from the Solanaceae. In J. A. Bailey, \& J. W. Mansfield (Eds.), Phytoalexins (pp. 81-105). New York: Wiley.

Lyr, H. (1963). Zur Frage des Streubbaus durch ektotrophe Mykorrhiza pilae. In: Rawald, W., Lyr, H., Mykorrhiza (123142). International Mykorrhiza-Symposium. Weimar, Jena.

Mańka, M. (1981). Cellulolitic and pectolytic activity of Fusarium isolates pathogenic to corn seedlings. Acta Microbiologica Polonica, 1, 25-32.

Monte, E., Bridge, P. D., \& Sutton, B. C. (1991). An integrated approach to Phoma systematics. Mycopathologia, 115, 89-103.

Nawar, H. F., \& Kuti, J. O. (2003). Wyerone acid phytoalexin synthesis and peroxidase activity as markers for resistance of broad beans to chocolate spot disease. Journal of Phytopathology, 151, 564-570.
Nilsson, R. H., Ryberg, M., Kristiansson, E., Abarenkov, K., Larsson, K. H., \& Koljalg, U. (2006). Taxonomic reliability of DNA sequences in public sequence databases: a fungal perspective. PLOS ONE, 1, e59.

Rai, M. K., Tiwari, V. V., Irinyi, L., \& Kövics, G. J. (2014). Advances in taxonomy of genus Phoma: polyphyletic nature and role of phenotypic traits and molecular systematics. Indian Journal of Microbiology, 54, 123-128.

Romanowska, I., Janowska, J., \& Bielecki, S. (2004). Optymalizacja procesu nagromadzania ksylanazy przez szczep Aspergillus niger IBT-90. Acta Scientiarum Polonorum. Biotechnologia, 3, 12-23.

Saitou, N., \& Nei, M. (1987). The neighbour-joining method: a new method for reconstructing phylogenetic trees. Molecular Biology and Evolution, 4, 406-425.

Saniewska, A., \& Budzianowski, J. (1997). The nature of red pigment formed in wounded and infected Hippeastrum tissues by Stagonospora curtissi (Berk.) Sacc. (Phoma narcissi). Acta Horticulturae, 430, 843-848.

Strzelczyk, E., \& Szpotański, T. (1989). Chitynolytic and proteolytic activity of Streptomycetes isolated from root-free soil, rhizosphere and mycorrhizosphere of pine (Pinus sylvestris L.). Biology and Fertility of Soils, 7, 365-369.

Swofford, D. L. (2003). PAUP*: Phylogenetic Analysis Using Parsimony (*and Other Methods) version $4 \mathrm{~b} 10$. Sunderland, MA, USA: Sinauer Associates.

Thompson, J. D., Gibson, T. J., Plewniak, F., Jeanmougin, F., \& Higgins, D. G. (1997). The CLUSTAL-windows interface: flexible strategies for multiple sequence alignment aided by quality analysis tools. Nucleic Acids Research, $25,4876-4882$.

Tonukari, N. J. (2003). Enzymes and fungal virulence. Journal of Applied Sciences and Environmental Management, 7, 5-8.

Van Etten, H. D., Matthews, D. E., \& Matthews, P. S. (1989). Phytoalexin detoxification: importance for pathogenicity and practical implications. Annual Review of Phytopathology, 27, 143-164.

Wink, M., \& Lehmann, P. (1996). Wounding- and elicitor-induced formation of coloured chalconesand flavans (as phytoalexins) in Hippeastrum $\times$ hortorum. Botanica Acta, 109, 412-421. 